\title{
环北太平洋地区现代植被中 $\mathrm{C}_{3} / \mathrm{C}_{4}$ 植物相对丰度与气候 条件关系研究
}

饶志国 ${ }^{(12)}$ ，朱照宇 ${ }^{(1)}$ ，贾国东 ${ }^{(1)}$ ，陈发虎 ${ }^{(2)}$, BARTON Loukas ${ }^{(4)}$ ，张家武 ${ }^{(2)}$ ，强明瑞 ${ }^{(2)}$

(1) 中国科学院广州地球化学研究所边缘海地质重点实验室, 广州 510640;

(2) 兰州大学西部环境教育部重点实验室, 兰州 730000;

(3) Department of Anthropology, University of California, Davis, CA 95616, USA;

(4) Katmai National Park and Preserve, King Salmon, AK 99613, USA

E-mail: raozhg@1zu.edu.cn

2009-06-01 收稿, 2009-11-26 接受

教育部科学技术研究重点项目(编号: 109151)、国家自然科学基金(批准号: 40672121, 40872111)和国家自然科学基金创新群体项目(批准号: 40721061)资助

摘要 按照一个统一的方法, 即以 $-24 \%$ 和 $-14 \%$ 作为纯 $\mathrm{C}_{3}$ 和纯 $\mathrm{C}_{4}$ 植被下表土总有机质碳同 位素组成 $\left(\delta^{13} \mathrm{C}_{\mathrm{TOC}}\right)$ 的端元值, 利用来自环北太平洋地区的中国东部、澳大利亚以及北美大平 原地区的表土 $\delta^{13} \mathrm{C}_{\mathrm{TOC}}$ 数据, 估算了这 3 个区域现代植被中 $\mathrm{C}_{3}$ 和 $\mathrm{C}_{4}$ 植物的相对生物量贡献 比例, 并和这 3 个区域相应的主要气候因素(年均温和年降水量)进行了对比, 进而探讨了现 代植被中 $\mathrm{C}_{3} / \mathrm{C}_{4}$ 植物相对丰度与气候条件之间的关系. 结果表明, 温度条件对 $\mathrm{C}_{4}$ 植物生物量 贡献具有决定性影响; 然而, 即使温度条件满足 $\mathrm{C}_{4}$ 植物生长的需要, 随着温度的进一步上升, 降水量应相应的下降, $\mathrm{C}_{4}$ 植物方能保持其优势地位. 这一结果与对现代 $\mathrm{C}_{4}$ 植物种属地理分布 调查获得的结论基本是一致的. 从而, 这一结果为上述区域过去地质历史时期 $\mathrm{C}_{3} / \mathrm{C}_{4}$ 植物相 对丰度变化记录的古环境解译提供了重要的参考资料。

关键词

有机质碳同位素

现代 $\mathrm{C}_{3} / \mathrm{C}_{4}$ 植物

相对丰度

气候因素

温度

降水
绝大多数陆生高等植物主要使用两种光合作用 途径固定大气 $\mathrm{CO}_{2}$, 合成自身有机质, 其中所有的乔 木、绝大部分灌木和草本植物使用 $\mathrm{C}_{3}$ 光合作用途径, 部分莎草、灌木和草本植物使用 $\mathrm{C}_{4}$ 光合作用途径 ${ }^{[1 \sim 4]}$. 由于生理过程的不同, 这两种光合作用类型植物的 碳同位素组成具有较为显著的差别, 并且在不同的 生态环境下具有不同的生长优势. 因此, 利用碳同位 素方法, 通过对地质历史时期局地陆地生态系统中 $\mathrm{C}_{3} / \mathrm{C}_{4}$ 植物相对丰度变化历史的研究, 可以进行相应 的古环境重建. 目前, 这一古环境重建的方法广泛应 用于全球的湖泊沉积物 ${ }^{[5 \sim 7}$ 、黄土/古土壤序列 ${ }^{[8 \sim 11]}$ 、 海洋沉积物 ${ }^{[12,13]}$ 等等研究载体中.

目前已有的对 $\mathrm{C}_{4}$ 植物生长和气候条件之间关系
的知识, 绝大部分是通过对现代 $\mathrm{C}_{4}$ 植物种属地理分 布的调查而获得的. 如殷立娟和李美荣 ${ }^{[14]}$ 曾对中国 大陆范围内 $\mathrm{C}_{4}$ 植物种属的地理分布及其与气候环境 条件之间的关系进行过系统的总结; 而 Sage 等人 ${ }^{[15]}$ 则对世界范围内 $\mathrm{C}_{4}$ 植物种属的地理分布进行了系统 的总结. 这些工作对深人认识 $\mathrm{C}_{4}$ 植物生长和气候条 件之间的关系, 做出了极其重要的贡献. 然而, $\mathrm{C}_{3} / \mathrm{C}_{4}$ 植物相对丰度一般是指来源于 $\mathrm{C}_{3}$ 和 $\mathrm{C}_{4}$ 植物的生物量 在局地初级生产力当中所占的比重, 这与 $\mathrm{C}_{4}$ 植物种 属的地理分布、或者其在局地生态系统所有植物种属 中所占有的比例具有概念上的差别. $\mathrm{C}_{4}$ 植物资源极少 的区域, 如北半球 $60^{\circ} \mathrm{N}$ 以北的区域, 目前该区域仅 发现 3 5 种 $\mathrm{C}_{4}$ 植物 ${ }^{[15]}, \mathrm{C}_{4}$ 植物在所有植物种属当中

英文版见: Rao Z G, Zhu Z Y, Jia G D, et al. Relationship between climatic conditions and the relative abundance of modern $\mathrm{C}_{3}$ and $\mathrm{C}_{4}$ plants in three regions around the North Pacific. Chinese Sci Bull, 2010, 55, doi: 10.1007/s11434-010-0101-y 
的比例和其相对丰度都接近于零. $\mathrm{C}_{4}$ 植物资源异常丰 富的区域, 如热带稀树草原(萨瓦纳植被), $\mathrm{C}_{4}$ 植物种 属在所有植物种属中可占到 $90 \%$ 以上，同样的，该区 域的 $\mathrm{C}_{4}$ 植物相对丰度也非常高 ${ }^{[15]}$. 但除这些特殊情 况以外的广大其他区域, $\mathrm{C}_{4}$ 植物种属分布和它的相对 生物贡献量有时可能会具有较大的差异. 无论如何, 沉积物碳同位素分析仅可能获得过去 $\mathrm{C}_{3} / \mathrm{C}_{4}$ 植物相对 生物量贡献, 而无法探知 $\mathrm{C}_{4}$ 植物种属比例的变化.

研究者已在不同区域利用表土总有机质碳同位 素来研究现代植被中 $\mathrm{C}_{3} / \mathrm{C}_{4}$ 植物相对丰度变化及其和 环境条件之间的关系. 来自 $34^{\circ} \sim 38^{\circ} \mathrm{N}$ 之间的黄土高 原中部地区的 18 个现代土壤样品的 $\delta^{13} \mathrm{C}_{\mathrm{TOC}}$ 值变化在 $-21.4 \%$ o - 24.8\%。之间，均值为 $-23.3 \%$ ，表明该区域 现代植被主要由 $\mathrm{C}_{3}$ 植物组成 ${ }^{[16]}$. Feng 等人 ${ }^{[17]}$ 对 $34^{\circ} \sim$ $52^{\circ} \mathrm{N}$ 之间, 从宝鸡附近的秦岭到接近蒙古和俄罗斯 边境的众多表土样品进行了总有机质碳同位素分析, 得到的结果表明该区域表土总有机质碳同位素都较 为偏负, 表明该区域现代植被同样以 $\mathrm{C}_{3}$ 植物为主; 虽然该区域 $42^{\circ} \sim 46^{\circ} \mathrm{N}$ 的表土总有机质碳同位素相对 较为偏正, 但该区域的采样点恰好处在沙漠和沙漠 草原的环境下, 很可能主要反映了 $\mathrm{C}_{3}$ 植物碳同位素 在更为干旱的环境下更为偏正 ${ }^{[18]}$. 这两个区域的表 土总有机质碳同位素都被用来分析和环境条件之间 的关系 ${ }^{[16,17,19]}$, 由于这两个区域的现代植被都以 $\mathrm{C}_{3}$ 植物为主, 因此它们很好地反映了 $\mathrm{C}_{3}$ 植物碳同位素 组成和气候环境条件之间的关系.

总体而言, 目前还缺乏比较好的较大空间范围 的现代植被当中 $\mathrm{C}_{3} / \mathrm{C}_{4}$ 植物相对丰度变化和气候环境 条件之间关系研究结果的系统总结, 这样的研究结 果无疑对利用过去 $\mathrm{C}_{3} / \mathrm{C}_{4}$ 植物相对丰度变化记录进行 古环境重建具有重要的参考意义. 本文利用一个统 一的估算方法, 以及先前研究当中获得中国东部地 $区^{[20,21]}$ 、北美大平原地区 ${ }^{[22]}$ 、澳大利亚地区 ${ }^{[23]}$ 的表 土总有机质碳同位素数据, 估算了这 3 个区域现代植 被当中 $\mathrm{C}_{3}$ 和 $\mathrm{C}_{4}$ 植物的相对生物量贡献, 并和采样点 的年均温和年降水量数据进行了对比, 从而在一个 较为广阔、气候和植被类型丰富的区域探讨了现代 $\mathrm{C}_{3} / \mathrm{C}_{4}$ 植物相对丰度和气候环境条件之间的关系.

\section{1 材料与方法}

尽管对现代植物的研究结果表明, 世界范围内 $\mathrm{C}_{3}$ 植物碳同位素组成分布在 $-20 \%$ $-34 \%$ 之间, 以
$-27 \%$ 附近出现的频率最高; 而 $\mathrm{C}_{4}$ 植物碳同位素组成 分布在-9\% - $19 \%$ 之间，以-13\% 附近出现的频率最

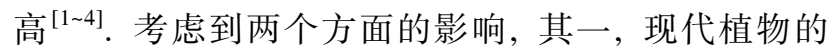
碳同位素组成在不同环境条件下可发生变化 ${ }^{[18,24]}$; 其二, 植物残体转化为土壤有机质的过程当中, 其碳 同位素组成会发生一定程度的改变 ${ }^{[16,25]}$, 这就使得 直接利用现代植物碳同位素组成数据( $-27 \%$ o和 $-13 \%$ ) 作为两端元值来估算 $\mathrm{C}_{3} / \mathrm{C}_{4}$ 植物相对丰度, 会产生较 大的偏差. 顾兆炎等人 ${ }^{[8]}$ 曾在参照北美大平原 ${ }^{[22]}$ 和 澳大利亚 ${ }^{[23]}$ 表土 $\delta^{13} \mathrm{C}_{\mathrm{TOC}}$ 研究结果的基础上, 将 $-24 \%$ 和-14\%o作为纯 $\mathrm{C}_{3}$ 和纯 $\mathrm{C}_{4}$ 植被下土壤 $\delta^{13} \mathrm{C}_{\mathrm{TOC}}$ 的两端元值来估算黄土高原多个剖面末次冰期至全 新世的 $\mathrm{C}_{3} / \mathrm{C}_{4}$ 植物相对丰度变化, 取得了良好的结果. 对不同估算方法的对比研究表明这是一种比较好的 利用 $\delta^{13} \mathrm{C}_{\mathrm{TOC}}$ 估算 $\mathrm{C}_{3} / \mathrm{C}_{4}$ 植物相对丰度的方法 ${ }^{[26]}$. 在 本项研究当中, 我们继续采用这一方法, 而将 $-19 \%$ 。 作为 $\mathrm{C}_{3}, \mathrm{C}_{4}$ 植物占优势地位的一个分界线, 亦即表土 $\delta^{13} \mathrm{C}_{\mathrm{TOC}}$ 数据>-14\% 代表了纯 $\mathrm{C}_{4}$ 植被 $\left(\mathrm{C}_{4}\right.$ 植物相对丰 度为 $100 \%), \delta^{13} \mathrm{C}_{\mathrm{TOC}}$ 数据介于 $-19 \%$ $-14 \%$ 。间代表 了 $\mathrm{C}_{4}$ 植物占优势地位的植被 $\left(\mathrm{C}_{4}\right.$ 植物相对丰度介于 $50 \%$ 100\%之间), $\delta^{13} \mathrm{C}_{\mathrm{TOC}}$ 数据介于-19\%o - 24\%o之间 代表了 $\mathrm{C}_{3}$ 植物占优势地位, 但 $\mathrm{C}_{4}$ 植物仍然存在的植 被 $\left(\mathrm{C}_{4}\right.$ 植物相对丰度介于 $0 \sim 50 \%$ 之间), $\delta^{13} \mathrm{C}_{\mathrm{TOC}}$ 数据 $<-24 \%$ o代表了纯 $C_{3}$ 植被 $\left(C_{4}\right.$ 植物相对丰度为 0$)$.

本文所用的表土 $\delta^{13} \mathrm{C}_{\mathrm{TOC}}$ 数据分别来源于中国东 部地区 ${ }^{[21]}$ 、北美大平原地区 ${ }^{[22]}$ 和澳大利亚 ${ }^{[23]}$, 其大 致分布的区域如图 1 所示. 我们先前的研究结果表明 中国东部地区众多表土 $\delta^{13} \mathrm{C}_{\mathrm{TOC}}$ 数据(图 2(a))和陆生 高等植物来源的具有明显奇偶优势的长链正构烷烃 $\left(n-C_{27}, n-C_{29}\right.$ 和 $n-C_{31}$ ) 碳同位素具有非常一致的空间 变化特征, 即在 $31^{\circ} \sim 40^{\circ} \mathrm{N}$ 之间整体较为偏正, 在 $40^{\circ} \mathrm{N}$ 以北区域集中在非常偏负的区域(除个别研究点 外, 基本都偏负于 $-24 \%$ ), 而在 $31^{\circ} \mathrm{N}$ 以南区域则数 据点较为离散, 但整体仍偏负于中纬度地区, 集中在 $<-19 \% o$ 的区域 ${ }^{[21]}$. 这样一个变化趋势也与来自中国 东部地区表土植硅体碳同位素研究结果 ${ }^{[27]}$ 相一致. 来自北美大平原地区的表土 $\delta^{13} \mathrm{C}_{\mathrm{TOC}}$ 数据 ${ }^{[22]}$ 则在 $30^{\circ} \sim 52^{\circ} \mathrm{N}$ 之间具有随着纬度升高而整体逐渐偏负的 变化特征(图 2(b)). 来自澳大利亚地区的表土 $\delta^{13} \mathrm{C}_{\mathrm{TOC}}$ 数据 ${ }^{[23]}$ 则在 $14^{\circ} \sim 25^{\circ} \mathrm{S}$ 之间的区域整体较为 偏正, 而向其南北两侧逐渐偏负, 到 $14^{\circ} \mathrm{S}$ 以北区域 和 $25^{\circ} \mathrm{S}$ 以南区域则整体偏负于-24\%o(图 2(c)). 

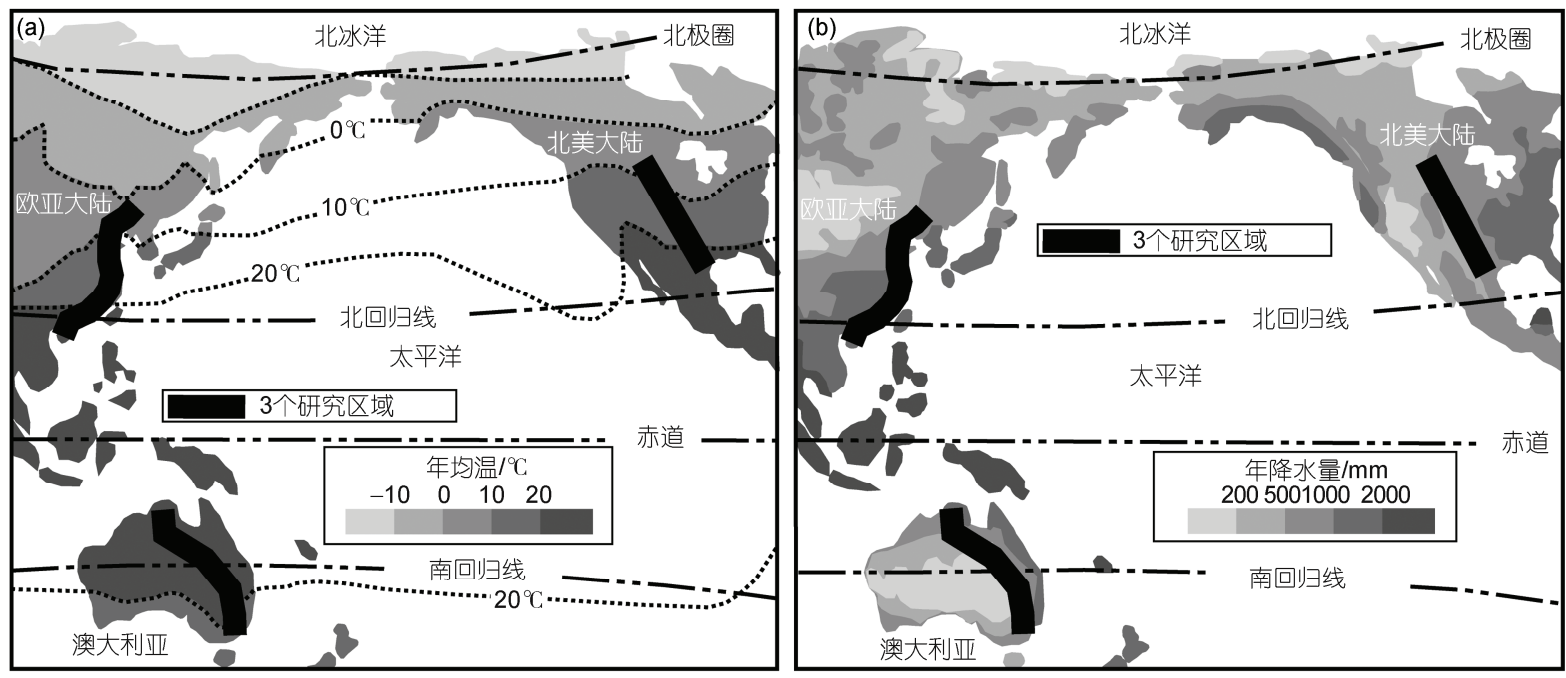

图 1 表土 $\delta^{13} \mathrm{C}_{\mathrm{TOC}}$ 数据来源区域以及环北太平洋地区年均温(a)和年降水量(b)空间分布示意图
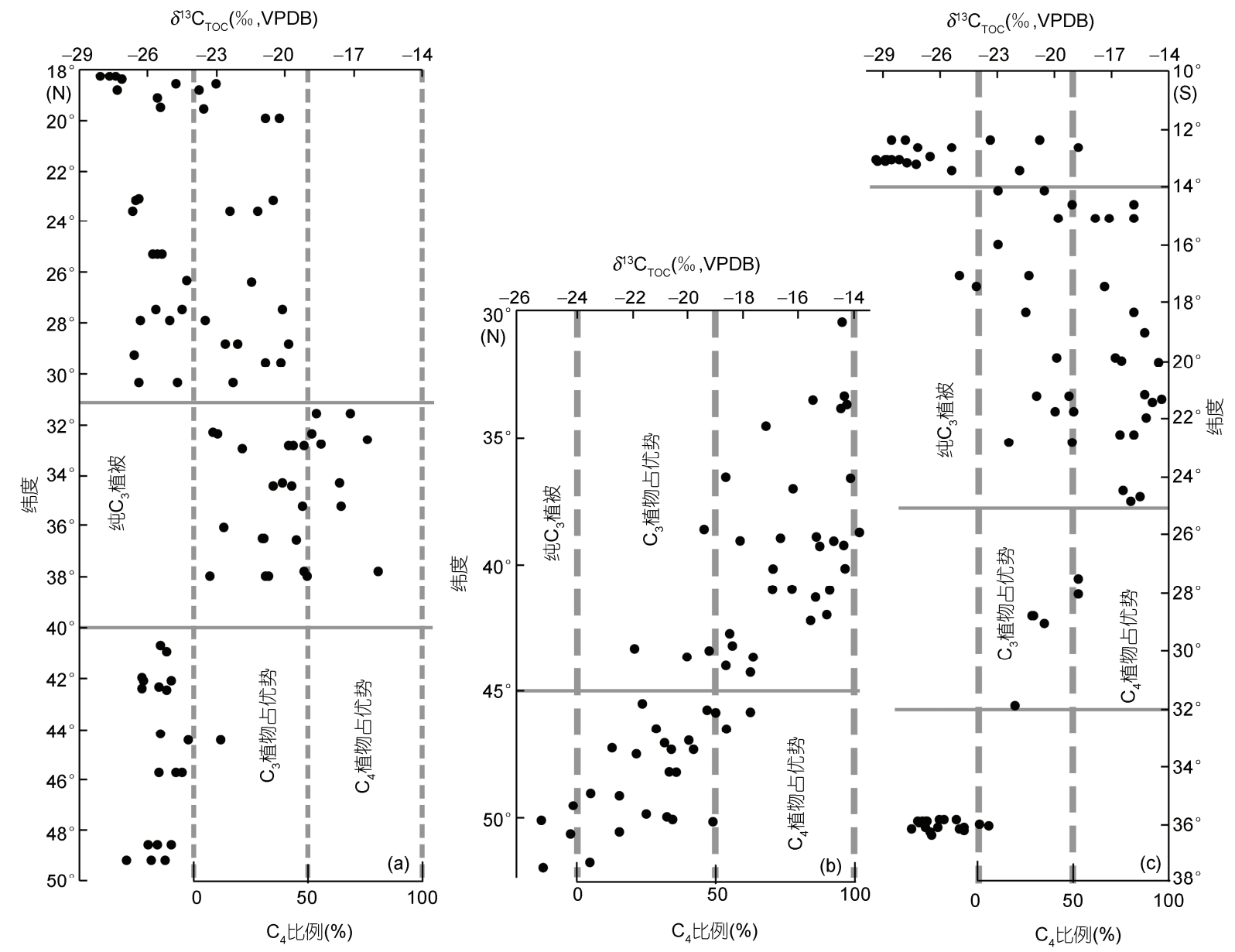

图 2 来自中国东部地区、北美大平原地区和澳大利亚地区表土 $\delta^{13} \mathrm{C}_{\mathrm{TOC}}$ 数据以及这 3 个区域估算的 $\mathrm{C}_{3} / \mathrm{C}_{4}$ 植物相对丰度沿 纬度的变化特征

(a) 源数据来自文献[21]; (b) 源数据来自文献[22]; (c) 源数据来自文献[23] 


\section{2 结果与讨论}

按照前述的估算方法, 利用来源于上述 3 个区域 的表土 $\delta^{13} \mathrm{C}_{\mathrm{TOC}}$ 数据, 估算了各个区域 $\mathrm{C}_{3} / \mathrm{C}_{4}$ 植物相 对丰度的空间变化特征, 结果如图 2 所示. 中国东部 地区 $18^{\circ} \sim 31^{\circ} \mathrm{N}$ 之间的区域为纯 $\mathrm{C}_{3}$ 植被或者以 $\mathrm{C}_{3}$ 植 物占优势地位的 $\mathrm{C}_{3} / \mathrm{C}_{4}$ 混合植被; $31^{\circ} \sim 40^{\circ} \mathrm{N}$ 之间的区 域为 $\mathrm{C}_{3}$ 植物和 $\mathrm{C}_{4}$ 植物混合植被, 局部地区以 $\mathrm{C}_{3}$ 植物 占优势地位, 也有部分地区分布有 $\mathrm{C}_{4}$ 植物占优势地 位的植被; $40^{\circ} \sim 50^{\circ} \mathrm{N}$ 之间的区域基本为纯 $\mathrm{C}_{3}$ 植物构 成的植被(图 2(a)). 北美大平原地区在 $30^{\circ} \mathrm{N}$ 至大约 $45^{\circ} \mathrm{N}$ 之间的区域为纯 $\mathrm{C}_{4}$ 植物构成的植被或者 $\mathrm{C}_{4}$ 植 物占优势地位的 $\mathrm{C}_{3} / \mathrm{C}_{4}$ 混合植被; $45^{\circ} \sim 50^{\circ} \mathrm{N}$ 之间的区 域大致为 $\mathrm{C}_{3}$ 植物占优势地位的 $\mathrm{C}_{3} / \mathrm{C}_{4}$ 混合植被; 而 $50^{\circ} \mathrm{N}$ 以北的区域则大致为纯 $\mathrm{C}_{3}$ 植物构成的植被(图 2(b)). 澳大利亚地区在 $10^{\circ} \sim 14^{\circ} \mathrm{S}$ 之间的区域为纯 $\mathrm{C}_{3}$ 植被或者以 $\mathrm{C}_{3}$ 植物占优势地位的植被; $14^{\circ} \sim 25^{\circ} \mathrm{S}$ 之 间的区域主体为 $\mathrm{C}_{3} / \mathrm{C}_{4}$ 混合植被, 纯 $\mathrm{C}_{3}$ 植物构成的植 被不复存在, 局部地区以 $\mathrm{C}_{3}$ 植物占优势地位, 也有 部分地区分布有 $C_{4}$ 植物占优势地位的植被, 甚至某 些研究点具有纯 $\mathrm{C}_{4}$ 植物构成的植被; $25^{\circ} \sim 32^{\circ} \mathrm{S}$ 之间 区域为 $\mathrm{C}_{3}$ 植物占优势地位的 $\mathrm{C}_{3} / \mathrm{C}_{4}$ 混合植被; 而 $32^{\circ} \mathrm{S}$ 以南区域则主体为纯 $\mathrm{C}_{3}$ 植物构成的植被(图 2(c)).

由于中国东部表土 $\delta^{13} \mathrm{C}_{\mathrm{TOC}}$ 研究点附近都有气象 站点记录了相应的气候数据 ${ }^{[20]}$, 而 Bird 和 Pousai ${ }^{[23]}$ 也提供了澳大利亚每个表土 $\delta^{13} \mathrm{C}_{\mathrm{TOC}}$ 研究点的年均温 和年降水量数据, 这使得我们可以较为详细的讨论 这两个区域 $\mathrm{C}_{3} / \mathrm{C}_{4}$ 植物相对丰度和年均温以及年降水 量之间的关系. 尽管植物生长具有一定的季节性, 利 用其生长季节的平均温度和降水来进行对比或许更 为合理, 考虑到如下 3 个因素: (1) 研究区域空间跨 度大, 各个研究点植物的生长季节必然不一致, 难以 确定具体的时段; (2) 各个研究地点生长季节的平均 温度、降水和当地的年均温、年降水量空间变化趋势 在整个研究区域基本应该还是一致的; (3) Bird 和 Pousai 仅提供了澳大利亚各个表土 $\delta^{13} \mathrm{C}_{\mathrm{TOC}}$ 研究点的 年均温和年降水量数据 ${ }^{[23]}$, 因此我们这里仅分析中 国东部地区和澳大利亚地区现代植被中 $\mathrm{C}_{3} / \mathrm{C}_{4}$ 相对丰 度和年均温、年降水量之间的关系, 获得的结果如图 3 所示. 对中国东部地区而言, 年降水量 $<500 \mathrm{~mm}$ 或 者 $>1800 \mathrm{~mm}$, 基本为纯 $\mathrm{C}_{3}$ 植被; 年降水 $500 \sim 1800$ $\mathrm{mm}, \mathrm{C}_{4}$ 植物可以生长, 但 $\mathrm{C}_{4}$ 植物占优势地位的地区
的年降水量仅分布在 $500 \sim 1200 \mathrm{~mm}$ (图 3(a)). 该区域 年均温低于 $12^{\circ} \mathrm{C}$ 时, 基本为纯 $\mathrm{C}_{3}$ 植物; 年均温在 12 $\sim 26^{\circ} \mathrm{C}$ 之间, $\mathrm{C}_{4}$ 植物都可以生长, 然而 $\mathrm{C}_{4}$ 植物能够占 据优势地位的地区的年均温仅集中在 $12 \sim 16^{\circ} \mathrm{C}$ 之间 (图 3(b)). 对澳大利亚地区而言, 年降水量 $<200 \mathrm{~mm}$ 区域, 基本为纯 $\mathrm{C}_{3}$ 植被; 年降水量在 200 800 mm, $\mathrm{C}_{4}$ 植物都可以生长; 年降水量在 $200 \sim 500 \mathrm{~mm}, \mathrm{C}_{4}$ 植 物可以占据优势地位(图 3(c)). 该区域年均温低于 $16^{\circ} \mathrm{C}$ 时, 基本为纯 $\mathrm{C}_{3}$ 植被; 年均温在 $16 \sim 28^{\circ} \mathrm{C}, \mathrm{C}_{4}$ 植 物可以生长; 年均温在 $21 \sim 28^{\circ} \mathrm{C}$ 之间, $\mathrm{C}_{4}$ 植物可以占 据优势地位(图 3(d)). 由此可见, 这两个区域 $\mathrm{C}_{3} / \mathrm{C}_{4}$ 植 物相对丰度和单一气候因素之间的差异比较大, 尤 其是 $\mathrm{C}_{4}$ 植物占优势地位的区域的气候因素差异比较 大. 因此, 我们进一步将这 2 个区域 $\mathrm{C}_{3} / \mathrm{C}_{4}$ 植物相对 丰度放到统一的年均温和年降水量坐标下进行比较, 得到的结果如图 4 所示. 考虑到北美大平原地区 $\mathrm{C}_{4}$ 植物占优势地位的区域的年均温高于中国东部地区 $\mathrm{C}_{4}$ 植物占优势地位的区域, 而年降水量高于澳大利 亚 $\mathrm{C}_{4}$ 植物占优势地位的区域(图 1), 因此, 我们也将 北美大平原地区 $\mathrm{C}_{4}$ 植物占优势地位的区域的年均温 和年降水量分布范围大致列于图 4. 可见, 年均温低 于 $12^{\circ} \mathrm{C}$ 时, 无论降水量怎么变化, 都为纯 $\mathrm{C}_{3}$ 植被; 年均温高于 $12^{\circ} \mathrm{C}$ 时, 在一个比较宽泛的降水量范围 内, $\mathrm{C}_{4}$ 植物都可以生长, 但随着年均温的逐步上升, $\mathrm{C}_{4}$ 植物能够占据优势地位的区域, 其年降水量逐步 下降.

Sage 等人 ${ }^{[15]}$ 对全球 $\mathrm{C}_{4}$ 植物种属地理分布总结的 结果显示, $60^{\circ} \mathrm{N}$ 以北区域仅有 $3 \sim 5$ 种 $\mathrm{C}_{4}$ 植物, 而 $45^{\circ} \mathrm{S}$ 以南区域, $\mathrm{C}_{4}$ 植物的种属也异常少; 旺罗等人 ${ }^{[28]}$ 曾对 对青藏高原地区 $\left(27^{\circ} 42^{\prime} \sim 40^{\circ} 57^{\prime} \mathrm{N}, 88^{\circ} 93^{\prime} \sim 103^{\circ} 24^{\prime} \mathrm{E}\right.$, 海拔 2210 5050 m 范围内)采集的 158 种植物进行了 碳同位素分析, 发现其中仅有 8 种植物属于 $\mathrm{C}_{4}$ 植物. 李明财等人 ${ }^{[29]}$ 依据对青海省范围内不同海拔地区采 集的 300 余种现代植物叶片的碳同位素测量, 并参阅 国内外已经发表的不同地区的 $\mathrm{C}_{4}$ 植物名录, 整理出 青海高原地区 3500 余种植物当中的 $\mathrm{C}_{4}$ 植物, 发现仅 有 52 种植物属于 $\mathrm{C}_{4}$ 植物. 上述高纬度和高海拔地区 共同的特点是温度相对比较低, 这显然与我们对现 代植被中 $\mathrm{C}_{3} / \mathrm{C}_{4}$ 植物相对丰度与气候环境条件分析结 果是一致的. 前述的黄土高原中部地区的研究结 果 ${ }^{[16,19]}$ 以及 Feng 等人 ${ }^{[17]}$ 对中东亚地区的研究结果中 $34^{\circ} \sim 40^{\circ} \mathrm{N}$ 之间区域的表土总有机质碳同位素相对同 

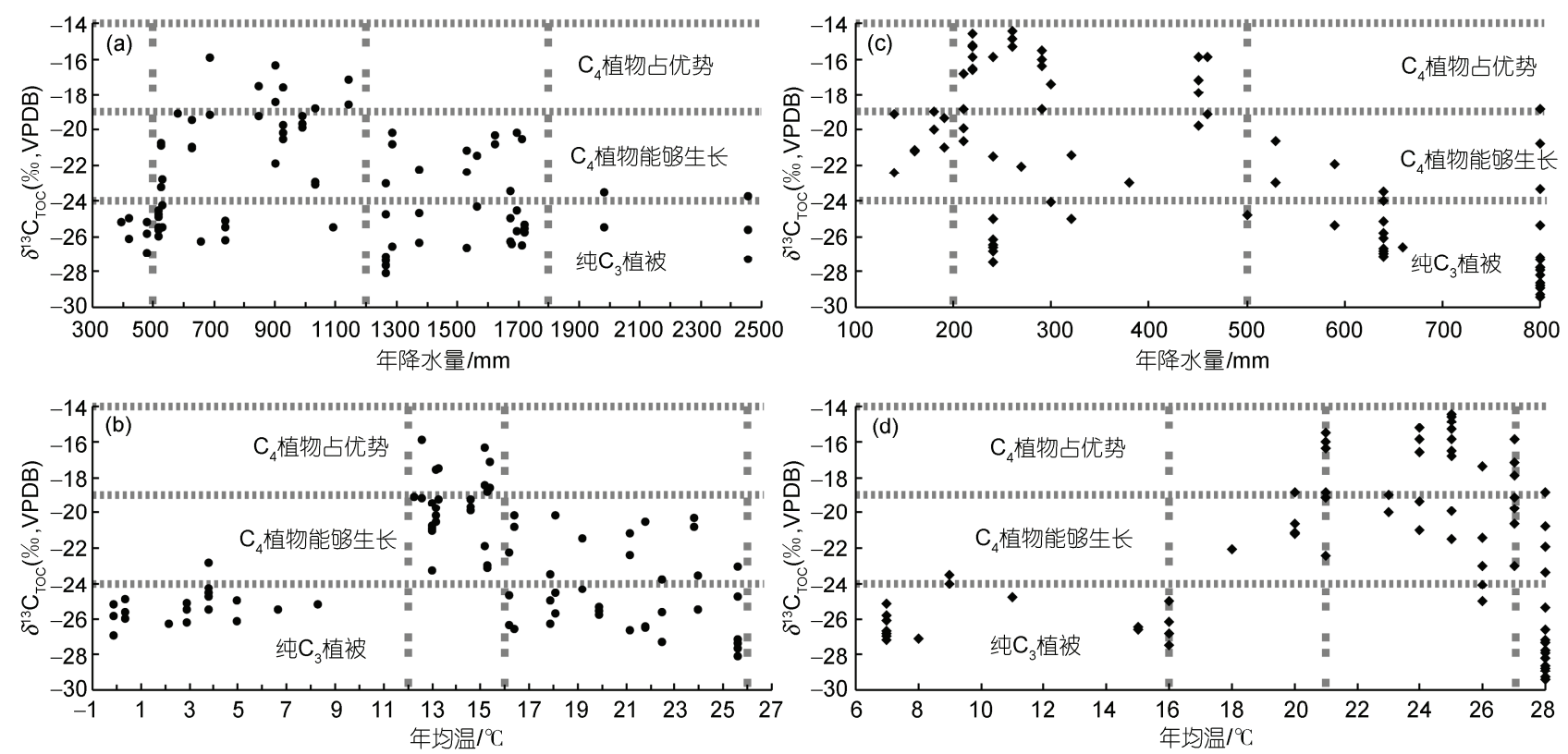

图 3 中国东部和澳大利亚地区 $\mathrm{C}_{4}$ 植物相对丰度和年平均降水量以及年平均温度之间的关系

(a) 中国东部地区 $\mathrm{C}_{4}$ 植物相对丰度和年平均降水量之间的关系; (b) 中国东部地区 $\mathrm{C}_{4}$ 植物相对丰度和年平均温度之间的关系; (c) 澳大利亚地 区 $\mathrm{C}_{4}$ 植物相对丰度和年平均降水量之间的关系; (d) 澳大利亚地区 $\mathrm{C}_{4}$ 植物相对丰度和年平均温度之间的关系

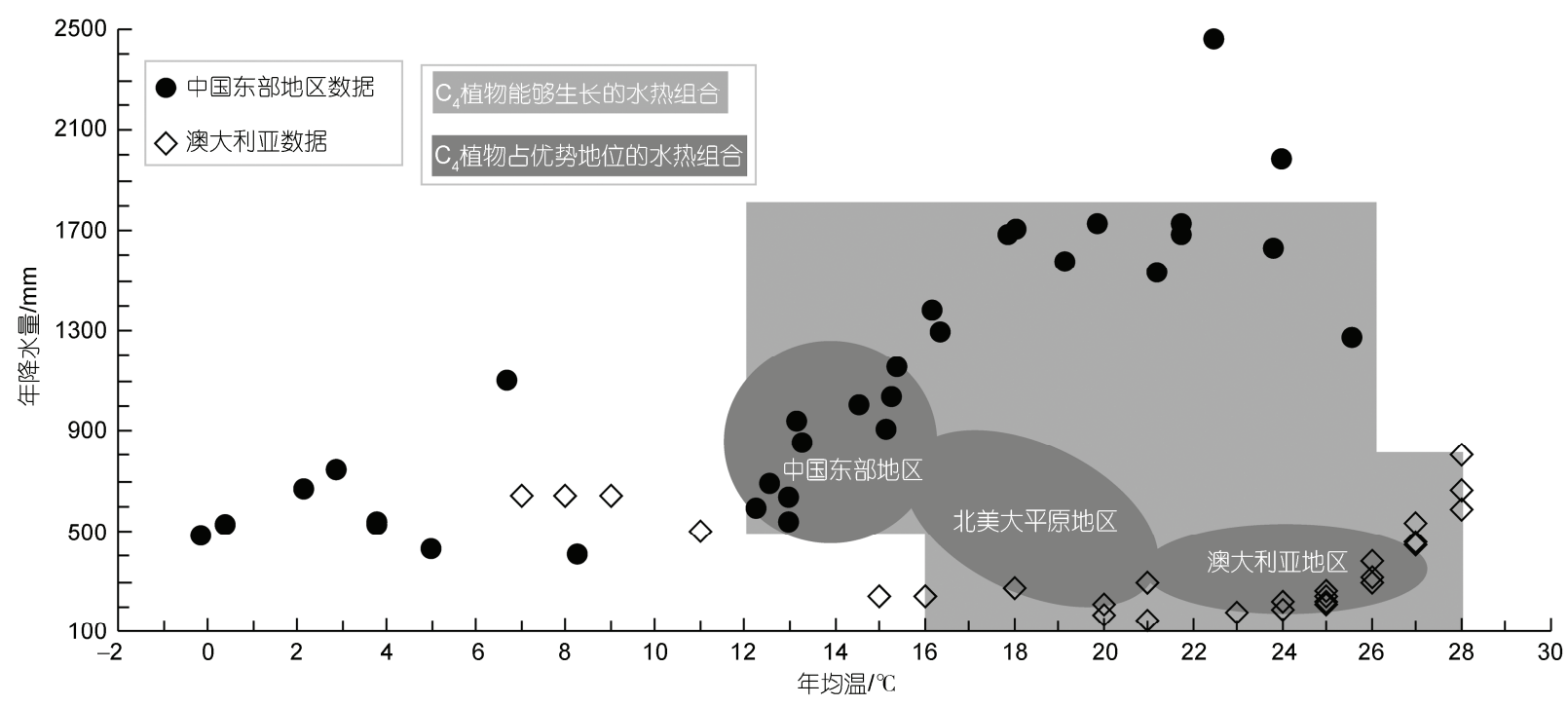

图 4 中国东部地区、澳大利亚地区以及北美大平原地区 $\mathrm{C}_{4}$ 植物相对丰度与温度和降水组合之间的关系

纬度的中国东部地区更为偏负，表明这两个区域中 现代植物以 $\mathrm{C}_{3}$ 植物为主, $\mathrm{C}_{4}$ 植物相对丰度比同纬度 的中国东部地区要低, 很可能是同纬度的内陆地区, 其温度要比沿海地区低(图 1), 这从一个侧面反映了 温度对 $\mathrm{C}_{4}$ 植物生长的重要性. 同时, 这两个区域相 对于同纬度的沿海地区要更为干旱一些(图 1), 这可
能表明过低的温度条件下，即使更为干旱也不能有 效地促进 $\mathrm{C}_{4}$ 植物的生长. 考虑到高温高湿的低纬度 地区往往发育雨林和季雨林植被, 高温但相对干旱 的低纬度地区则有可能发育典型的 $\mathrm{C}_{4}$ 植被-热带稀树 草原植被, 这显然也符合我们获得的认识, 即 $\mathrm{C}_{4}$ 植 物生长的温度条件满足之后, 随着年均温的逐步上 
升, 其年降水量应逐步下降, $\mathrm{C}_{4}$ 植物才能够保持其占 据优势地位.

\section{3 结论}

利用一个统一的方法, 估算了来源于中国东部 地区、澳大利亚地区和北美大平原地区表土总有机质 碳同位素所代表的局地 $\mathrm{C}_{4}$ 植物对初级生产力贡献的 比例, 并较为定量地讨论了 $\mathrm{C}_{4}$ 植物相对丰度和气温、 降水量之间的关系, 进而在统一的温度和降水量坐
标下讨论了 $\mathrm{C}_{4}$ 植物相对丰度和水热组合之间的关系. 结果表明, 温度过低的区域, 无论降水量怎么变化, $\mathrm{C}_{4}$ 植物相对丰度都极为有限. 温度条件满足之后, $\mathrm{C}_{4}$ 植物在一个较宽的降水量范围内都可以生长, 但其 能够占据优势地位的降水量范围有限, 更为重要的 是, 随着温度的进一步上升, 降水量应相应的减少, $\mathrm{C}_{4}$ 植物方能保持其优势地位. 对于上述区域依据沉 积物重建的过去 $\mathrm{C}_{3} / \mathrm{C}_{4}$ 植物相对丰度变化记录的古气 候解译, 我们的结果具有重要的参考价值.

\section{参考文献}

1 Deines P. The isotopic composition of reduced organic carbon. In: Fritz P, Fontes J C, eds. Handbook of Environmental Isotope Geochemistry, Volume 1, The Terrestrial Environment, A. Amsterdam: Elsevier Scientific Publishing Company, 1980. 339-345

2 O'Leary M H. Carbon isotope in photosynthesis. Bioscience, 1988, 38: 328-336

3 O'Leary M H. Carbon isotope fractionation in plants. Phytochemistry, 1981, 20: 553-567

4 Farquhar G D, Ehleringer J R, Hubick K T. Carbon isotope discrimination and photosynthesis. Annu Rev Plant Physiol Mol Biol, 1989, 40: $503-537$

5 Street-Perrott F A, Huang Y S, Perrot R A, et al. Impact of lower atmospheric carbon dioxide on tropical mountain ecosystems. Science, 1997, 278: $1422-1426$

6 Huang Y S, Street-Perrott F A, Metcalfe S E, et al. Climate change as the dominant control on glacial-interglacial variation in $\mathrm{C}_{3}$ and $\mathrm{C}_{4}$ plant abundance. Science, 2001, 293: 1647-1651

7 Brincat D, Yamada K, Ishiwatayi R, et al. Molecular-isotopic stratigraphy of long-chain $n$-alkanes in Lake Baikal Holocene and glacial age sediments. Org Geochem, 2000, 31: 287-294

8 顾兆炎, 刘强, 许冰, 等. 气候变化对黄土高原末次盛冰期以来的 $\mathrm{C}_{3} / \mathrm{C}_{4}$ 植物相对丰度的控制. 科学通报, 2003, 48: $1458-1464$

9 Zhang Z H, Zhao M X, Lü H Y, et al. Lower temperature as the main cause of $\mathrm{C}_{4}$ plant declines during the glacial periods on the Chinese Loess Plateau. Earth Planet Sci Lett, 2003, 214: 467-481

10 Liu W G, Huang Y S, An Z S, et al. Summer monsoon intensity controls $\mathrm{C}_{4} / \mathrm{C}_{3}$ plants abundance during the last $35 \mathrm{ka}$ in the Chinese Loess Plateau: Carbon isotope evidence from bulk organic matter and individual leaf waxes. Palaeogeogr Palaeoclimatol Palaeoecol, 2005, 220: $243-254$

11 陈发虎, 饶志国, 张家武, 等. 陇西黄土高原末次冰期有机碳同位素变化及其意义. 科学通报, 2006, 51: 1310一1317

12 Jia G D, Peng P A, Zhao Q H, et al. Changes in terrestrial ecosystem since 30 Ma in East Asia: Stable isotope evidence from black carbon in the South China Sea. Geology, 2003, 31: 1093-1096

13 Yamada K, Ishiwatari R. Carbon isotopic composition of long-chain $n$-alkanes in the Japan Sea sediments: Implication for paleoenvironmental changes over the past $85 \mathrm{kyr}$. Org Geochem, 1999, 30: 367-377

14 殷立娟, 李美荣. 中国 $\mathrm{C}_{4}$ 植物的地理分布与生态学研究-中国 $\mathrm{C}_{4}$ 植物及其与气候环境的关系. 生态学报, 1997, 17: 350一 363

15 Sage R F, Wedin D A, Li M R. The biogeography of $\mathrm{C}_{4}$ photosynthesis: Patterns and controlling factors. In: Sage R F, Monson R K, eds. $\mathrm{C}_{4}$ Plant Biology. San Diego, California: Academic Press, 1999. 313-373

16 刘卫国, 宁有丰, 安芷生, 等. 黄土高原现代土壤和古土壤有机碳同位素对植被的响应. 中国科学 D 辑：地球科学, 2002, 32: 830836

17 Feng Z D, Wang L X, Ji Y H, et al. Climatic dependency of soil organic carbon isotopic composition along the S-N Transect from $34^{\circ} \mathrm{N}$ to $52^{\circ} \mathrm{N}$ in central-east Asia. Palaeogeogr Palaeoclimatol Palaeoecol, 2008, 257: 335-343

18 王国安, 韩家惁, 刘东生. 中国北方黄土区 $\mathrm{C}_{3}$ 草本植物碳同位素组成研究. 中国科学 $\mathrm{D}$ 辑: 地球科学, 2003, 33: 550-556

19 An Z S, Huang Y S, Liu W G, et al. Multiple expansions of $\mathrm{C}_{4}$ plant biomass in East Asia since 7 Ma coupled with strengthened monsoon circulation. Geology, 2005, 33, 705-708

20 饶志国. 中国东部表土总有机质碳同位素和正构烷烃碳、氢同位素空间变化特征及其古环境意义. 博士学位论文. 广州：中国科学 院广州地球化学研究所, 2007. 19-39

21 饶志国, 贾国东, 朱照宇, 等. 中国东部表土总有机质碳同位素和长链正构烷烃碳同位素对比研究及其意义. 科学通报, 2008, 53: $2077-2084$ 
22 Tieszen L L, Reed B C, Bliss L B, et al. NDVI, $\mathrm{C}_{3}$ and $\mathrm{C}_{4}$ production and distributions in Great Plains grassland land cover classes. Ecol Appl, 1997, 7: 59-78

23 Bird M I, Pousai P. Variations of Delta ${ }^{13} \mathrm{C}$ in the surface soil organic carbon pool. Glob Biogeochem Cycle, 1997, 11: 313-322

24 王国安, 韩家森, 周力平, 等. 中国北方黄土区 $\mathrm{C}_{4}$ 植物稳定碳同位素组成的研究. 中国科学 $\mathrm{D}$ 辑: 地球科学, 2005, 35: 1174一 1179

25 王国安. 稳定碳同位素在第四纪古环境研究中的应用. 第四纪研究, 2003, 23: 471-484

26 饶志国, 陈发虎, 曹洁, 等. 黄土高原西部地区未次冰期和全新世有机碳同位素变化与 $\mathrm{C}_{3} / \mathrm{C}_{4}$ 植被类型转换研究. 第四纪研究, 2005 , 25: $107-114$

27 王永吉, 吕厚远, 王国安, 等. $\mathrm{C}_{3}, \mathrm{C}_{4}$ 植物和现代土壤中硅酸体碳同位素分析. 科学通报, 2000, 45: 978一 982

28 旺罗, 吕厚远, 吴乃琴, 等. 青藏高原高海拔地区 $\mathrm{C}_{4}$ 植物的发现. 科学通报, 2004, 49: 1290-1293

29 李明财, 易现峰, 张晓爱, 等. 青海高原高寒地区 $\mathrm{C}_{4}$ 植物名录. 西北植物学报, 2005, 25: 1046-1050

\section{中国科学：地球科学}

\section{第 40 卷 第 4 期 2010 年 4 月}

目次

\section{评述}

地质流体状态方程.

\section{论文}

北祁连造山带老君山组沉积地球化学与物源分析 …………………………………………………….... 414

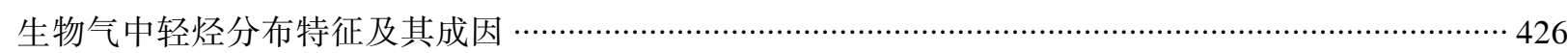

准噶尔盆地腹部超压顶面附近碳酸盐胶结带的成因机理 …………………………………………….... 439

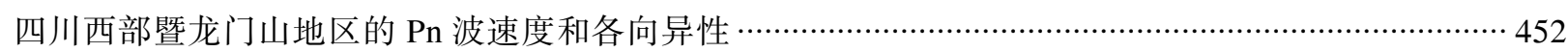

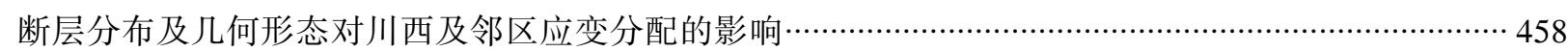

雷达探测仪对月球次表层结构的探测模拟方法 ………………………………………………………. 473

甘肃临潭陈旗磨沟遗址人牙结石中淀粉粒反映的古人类植物性食物……………………………………. 486

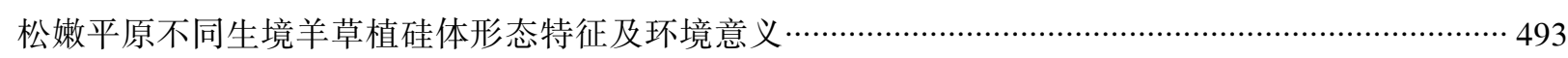

数值模拟定量探索地形起伏及浮力在驱动地下水流中的相对重要性………………………………………5 503

CMAQ 模式卫星产品源同化模型及其在空气质量预报中的应用研究…………………………………. 511

基于时差法三维定位系统对闪电放电过程的观测研究……………………………………………………5 523 